\title{
Changes of Cognitive Function and Fatigue following Chemotherapy in Patients with Gastrointestinal Cancer: A Prospective Controlled Study
}

\author{
Oh, Pok-Ja' $\cdot$ Moon, Sun $\mathrm{Mi}^{2}$ \\ ${ }^{1}$ Department of Nursing, Sahmyook University, Seoul; ${ }^{2}$ Surgical Department, Korea Cancer Center Hospital, Seoul, South Korea
}

Purpose: This study was to identify changes in cognitive function and fatigue following chemotherapy in patients with stomach or colorectal cancer. Methods: Of the participants, 67 underwent adjuvant chemotherapy, while 66 healthy participants made up the comparison group. Three assessment tools were used: 1) the Korean Mini-Mental State Examination; 2) Everyday Cognition; 3) Functional Assessment of Chronic Illness Therapy-Fatigue. The questionnaires were administered in three stages, before chemotherapy, towards the end of chemotherapy, and 6 months after the final chemotherapy session. Data were analyzed using descriptive statistics and repeated measures analysis of variance (RM ANOVA). Results: At the post-chemotherapy stage, $38.8 \%$ of the patients who underwent adjuvant chemotherapy complained of subjective cognitive impairment and reported greater difficulty in the cognitive domains of attention and concentration, memory, and executive function. RM ANOVA revealed a significant decline in cognitive function after chemotherapy. However, improvement was observed six months after the completion of chemotherapy ( $\mathrm{F}=42.68, p<$ .001). Cancer-related fatigue also showed similar patterns as observed in the case of cognitive function ( $\mathrm{F}=44.76, p<.001)$. Conclusion: Chemotherapy was associated with increased cognitive decline and fatigue in cancer patients with cancer. Nursing intervention programs need to be developed to counteract cognitive decline and fatigue in patients undergoing chemotherapy.

Key Words: Chemotherapy, Cognitive dysfunction, Fatigue, Longitudinal study

\section{INTRODUCTION}

Chemotherapy-related cognitive impairment (CRCI) is one of the most frequently reported side effects of chemotherapy. ${ }^{1)}$ About 15 70\% of cancer patients experience a decline in memory, face problems with attention, and complain of an inability to multitask following chemotherapy. ${ }^{2)}$ and $17 \sim 35 \%$ of these cases persist long-term. ${ }^{1,3)}$ Even if cognitive decline in cancer patients is mild, it can have a negative impact on their quality of life due to the difficulties it can cause in daily living and work. ${ }^{1,4)}$ CRCI primarily presents with abnormalities in pathways connecting the frontal lobe and the subcortical regions, as well as hippocampal damage, ${ }^{5)}$ leading to the impairment of memory and working memory (immediate memory), attention, and information processing

주요어: 항암화학요법, 인지손상, 피로, 종단적 연구

${ }^{*}$ This research was supported by Basic Science Research Program through the National Research Foundation of Korea (NRF) funded by the Ministry of Education (2014R1A1A2053517)

Address reprint requests to: Oh, Pok-Ja

Department of Nursing, Sahmyook University,

815 Hwarang-ro, Nowon-gu, Seoul 01795, Korea

Tel: +82-2-3399-1589 Fax:+82-2-3399-1594 E-mail: ohpj@syu.ac.kr

Received: Jun 11, 2019 Revised:Sep 7, 2019 Accepted:Sep 9, 2019

This is an Open Access article distributed under the terms of the Creative Commons Attribution NoDerivs License. (http://creativecommons.org/licenses/by-nd/4.0/) If the original work is properly cited and retained without any modification or reproduction, it can be used and re-distributed in any format and medium. speed. ${ }^{6}$ Cognitive function includes receptive functions such as selecting, acquiring, and unifying information, memory and learning, which involves storage and retrieval, mental organization of information and organized thinking, as well as expressive functions such as behavior and communication of information. ${ }^{7)}$

In terms of anticancer agents that affect CRCI, metabolic inhibitors (e.g., 5-FU, methotrexate), alkylating agents (cyclophosphamide, carmustine), and paclitaxel are reported to be toxic to neural progenitor cells and oligodendrocytes, which form the myelin sheaths in the central nervous system. ${ }^{8,9}$ These anticancer agents are commonly prescribed to patients with stomach or colorectal cancer, which are the most prevalent cancers in Korea. The symptoms and severity of CRCI are affected by various factors, including the cumulative dose of anticancer agents, age, and nutritional status. ${ }^{10)}$

Interest in CRCI has prompted research in diverse areas, including the treatment agents, as well as the incidence, duration, and extent of cognitive impairment. So far, basic research to manage cognitive decline in cancer patients has focused on investigating the causes of chemotherapy-related cognitive decline. Most studies that have investigated the effects of anticancer treatment itself, including drug dose (standard vs high dose) and hormone therapy, on cognitive function have dealt with breast cancer patients. ${ }^{6,11,12)}$ Thus, further research is required to determine 
whether changes in cognitive function differ in other types of cancer, such as stomach and colorectal cancer. ${ }^{13)}$ In addition, most studies have used a cross-sectional evaluation of cognitive impairment in a specific type of cancer. These studies do not control for cognitive impairment that developed before chemotherapy and impact of the severe symptoms and psychological distress caused by chemotherapy on cognitive function. ${ }^{14)}$ Therefore, longitudinal studies need to be performed to minimize these limitations and ascertain the patterns of change. Furthermore, cognitive function may change with time, and thus, a comparative group is needed for internal validity.

Fatigue is the most common symptom experienced by cancer patients in relation to chemotherapy, and it is the most reported factor associated with cognitive decline. ${ }^{15)}$

Chemotherapy causes toxic injury to cells, and the resulting inflammatory response can cause fatigue due to excessive cytokine production. ${ }^{15)}$ Interventions to promote cognitive function in cancer patients will need to include an understanding and management of patterns of fatigue.

Therefore, the present study aims to ascertain patterns of change of cognitive impairment and fatigue from the start of chemotherapy to the follow-up of chemotherapy. We examined patients with stomach or colorectal cancer, both of which have rarely been studied in this context. The results from this prospective study will provide directions for the development of programs to evaluate and provide intervention to patients who experience changes in cognitive function and fatigue after chemotherapy.

\section{METHODS}

\section{Study design}

This study used a prospective controlled design, which was consisted of investigation group (adjuvant chemotherapy group) and comparison group (healthy participants).

\section{Participants}

There were a total of 133 participants. Of the participants, 67 were treated with adjuvant chemotherapy and they were from a previous study, examining the change of cancer symptom, depression, and quality of life in chemotherapy patients. ${ }^{16)}$ Patients suffering from stomach or colorectal cancer from two hospitals in Seoul were invited to be part of the study, before the start of adjuvant chemotherapy. Eligible partici- pants were those who were over 18 years old and scheduled to receive an adjuvant chemotherapy regimen that included fluorouracil and oxaliplatin. Exclusion criteria included receiving neo-adjuvant chemotherapy, history of stroke dementia or a degenerative disease, and alcohol or drug abuse that might affect any neuropsychological test performance. Of the 74 patients who were invited, 67 (90.5\%) patients participated in the study; three died of their disease, three could not be contacted and one did not complete the baseline assessment. The comparison group was a sample of convenience comprising friends and family of healthy people from a local group. They were selected based on the matching variables such as age (plus or minus 1 year), sex and education level. Of these 67 healthy participants, 66 (98.5\%) participated in the study; 1 did not complete the follow-up assessment. The sample size needed for repeated measures analysis of variance was calculated using a $\mathrm{G}^{\star}$ Power program 3.1. ${ }^{17)}$ A sample size of 74 subjects was required for a two-sided RM ANOVA test with a significance level ( $\alpha$ ) of .05 , a power of .80 , an effect size $\left(\mathrm{f}^{2}\right)$ of 0.15 , a correlation of 0.5 and 3 measures in two groups. We used an effect size of 0.15 based on a prior study by Park \& Bae; ${ }^{18)}$ this study reported small effect sizes $(\mathrm{d}=-0.02 \sim 0.26)$ of chemotherapy on cognitive function in the meta-analysis of CRCI in breast cancer patients. Of the 141 participants initially recruited, 133 (94.3\%) completed the neuropsychological test questionnaire.

\section{Ethical considerations}

This study was approved by the institutional review boards of a $\mathrm{K}$ hospital in Seoul (IRB No. K-1405-002-039). Patients received information on the eligibility criteria and, purpose and procedure of this study from the cooperating nurse researcher. Potentially eligible participants were provided with written, informed consent forms assuring confidentiality regarding all information, and voluntary withdrawal was guaranteed for all participants without any adverse effects.

\section{Procedure}

The questionnaires were administered in three stages: before chemotherapy ( $1 \sim 3$ days before the start of the chemotherapy), towards the end of chemotherapy (1 2 days after the completion of chemotherapy), and six months after the final chemotherapy session. Assessments were individually administered and clinical data were collected from electronic medical records. In case of comparison group, the questionnaires were administered after collecting the data of every 10 chemotherapy patients based on the matching variables. Data collection was conducted from 
October, 2014 to May, 2016 by using structured questionnaires.

\section{Measures}

\section{1) Cognitive function}

We used the Korean version of Everyday Cognition (ECog) developed by Farias \& Mungas to measure self-reported cognitive decline. ${ }^{19}$ The ECog is a 39-question survey with 6 subscales. Questions are rated on a four-point scale ranging from 1 (no change), 2 (occasionally worse), 3 (consistently worse), to 4 (consistently much worse), comparing the perceived daily cognitive functioning from previous years ago to the present. Higher scores indicate greater cognitive decline. In the previous research, the optimal cutoff point for impaired cognitive function was $1.81{ }^{20)}$ We used a 2.0 cutoff point for impaired cognitive function. The a reliability in this study was 96 .

To evaluate the objective cognitive function, the Korean Mini Mental State Examination (KMMSE) was used. ${ }^{21)}$ The MMSE comprises 21 separate items representing orientation, verbal repetition, verbal recall, naming reading, writing, coping, and following directions. ${ }^{22)}$ This questionnaire is scored between 0 (worst possible score) and 30 (perfect score) points. Scores $\geq 24$ points are often considered to be normal values. Based on the criteria from previously conducted research with cancer patients, ${ }^{23)}$ scores $<23$ points, score from 24 to 26 points, and scores from 27 to 30 points were classified to indicate the level of cognitive function. We used a 26 points or less cutoff point for decline cognitive function.

\section{2) Fatigue}

The Korean version of the Functional Assessment of Cancer TherapyFatigue (FACT-F) scale was used. It consists of 13 items rated on a 5-point Likert scale $(0=$ not at all to $4=$ very much so). Higher scores indicate greater fatigue. Originally developed for use with cancer patients and Cronbach's a was $0.93 .{ }^{24)}$ The Cronbach's a was .86 in the present study.

\section{3) Demographic and clinical characteristics}

Data regarding hemoglobin and chemotherapy regimen were gathered from medical records and others were through the questionnaire.

\section{Statistical analysis}

The Statistical Package for the Social Sciences version 21.0 was used for all statistical analyses. Descriptive statistics were used to describe sample characteristics and assess the distribution of all variables. Cogni- tive function and fatigue, in accordance with the general characteristics of the participant, were examined using a t-test and ANOVA, while Scheffé's method was used as the post hoc test. Baseline group differences on demographic variables were examined using independent samples t-tests and chi-squared tests. Correlations among the variables were examined using Pearson correlation coefficients. A probability level of 0.05 was used for statistical significance. The statistical significance of the changes in the number of participants experiencing cognitive impairment from baseline to follow-up was assessed using the Cochran Q test. ${ }^{25)}$ Group comparisons on cognitive function and fatigue were made at three time points, using repeated measures ANOVA. Bonferroni was used for post hoc comparisons.

\section{RESULTS}

The study consisted of 133 participants. Sixty-seven of them belonged to the chemotherapy group and while 66 of healthy participants formed the comparison group. There were no statistically significant baseline differences between the two groups in terms of gender, age, marital status, education, monthly income. However, there were more employed participants in the comparison group (Table 1). Men accounted for $55.2 \%$ of the participants in the chemotherapy group, and men accounted for $40.9 \%$ of the participants in the comparison group. The mean age was 54.99 years (standard deviation [SD], 9.39) in the chemotherapy group and 56.06 years (SD, 8.08) in the comparison group. A majority (67.2 74.2\%) of the participants were aged 50 60 years in the both groups. Furthermore, a majority of the participants were married; $45.5 \%$ of the chemotherapy group had a high school education; and $42.4 \%$ had graduated from middle school or less in the comparison group.

In $88.1 \%$ of the cases, the cancer type was colorectal cancer. The distribution of disease stages was as follows: stage I, II, 31.3\%; stage III, $61.2 \%$; and stage IV, 7.5\%. Chemotherapy regimens that received were fluorouracil + leucovorin and/or oxaliplatin, 67.2\%; Oxaliplatin + xeloda $32.8 \%$. The average hemoglobin level was 12.20 (SD, 1.53) g/dL (Table 1).

\section{Cognitive function and fatigue according to the general characteristics of the participant}

There were no significant differences on self- reported cognitive decline and fatigue according to the general characteristics of the chemotherapy group. In the objective cognitive function, married participants showed greater cognitive function $(t=16.93, p<.001)$. There were no sig- 
Table 1. Baseline Characteristics of the Participants

$(N=133)$

\begin{tabular}{|c|c|c|c|c|c|c|}
\hline \multirow[t]{2}{*}{ Variables } & \multirow[t]{2}{*}{ Categories } & \multirow{2}{*}{$\begin{array}{l}\mathrm{n}(\%) \text { or } \\
\mathrm{M} \pm \mathrm{SD}\end{array}$} & \multirow{2}{*}{$\begin{array}{c}\text { Chemotherapy } \\
\text { group }(\mathrm{n}=67)\end{array}$} & \multirow{2}{*}{$\begin{array}{c}\text { Comparative } \\
\text { group }(\mathrm{n}=66) \\
\mathrm{n}(\%) \text { or } \mathrm{M} \pm \mathrm{SD}\end{array}$} & \multirow[t]{2}{*}{$x^{2}$ or $\mathrm{t}$} & \multirow[t]{2}{*}{$p$} \\
\hline & & & & & & \\
\hline Gender & $\begin{array}{l}M \\
F\end{array}$ & $\begin{array}{l}64(48.1) \\
69(51.9)\end{array}$ & $\begin{array}{l}37(55.2) \\
30(44.8)\end{array}$ & $\begin{array}{l}27(40.9) \\
39(59.1)\end{array}$ & -1.66 & .100 \\
\hline Age (yr) & $\begin{array}{l}<50 \\
51 \sim 55 \\
56 \sim 60 \\
>61\end{array}$ & $\begin{array}{l}39(29.3) \\
35(26.3) \\
23(17.3) \\
36(27.1)\end{array}$ & $\begin{array}{c}22(32.8) \\
16(23.9) \\
10(14.9) \\
19(28.4) \\
54.99 \pm 9.39\end{array}$ & $\begin{array}{c}17(25.8) \\
19(28.8) \\
13(19.7) \\
17(25.8) \\
56.06 \pm 8.08\end{array}$ & -0.33 & .746 \\
\hline Marital status & $\begin{array}{l}\text { Yes } \\
\text { No }\end{array}$ & $\begin{array}{r}111(83.5) \\
22(16.5)\end{array}$ & $\begin{array}{l}54(80.6) \\
13(19.4)\end{array}$ & $\begin{array}{r}57(86.4) \\
9(13.6)\end{array}$ & 0.89 & .375 \\
\hline Education & $\begin{array}{l}\leq \text { Middle school } \\
\text { High school } \\
\geq \text { College }\end{array}$ & $\begin{array}{l}47(35.6) \\
56(42.4) \\
29(22.0)\end{array}$ & $\begin{array}{l}19(28.8) \\
30(45.5) \\
17(25.8)\end{array}$ & $\begin{array}{l}28(42.4) \\
26(39.4) \\
12(18.2)\end{array}$ & 1.63 & .104 \\
\hline Occupation & $\begin{array}{l}\text { Employed } \\
\text { Unemployed }\end{array}$ & $\begin{array}{l}74(56.5) \\
57(43.5)\end{array}$ & $\begin{array}{l}26(38.8) \\
41(61.2)\end{array}$ & $\begin{array}{l}48(75.0) \\
16(25.0)\end{array}$ & 4.46 & $<.001$ \\
\hline $\begin{array}{l}\text { Monthly income } \\
(10,000 \text { won })\end{array}$ & $\begin{array}{l}<200 \\
200 \sim 399 \\
400 \sim 599 \\
\geq 600\end{array}$ & $\begin{array}{l}51(38.6) \\
50(37.9) \\
21(15.9) \\
10(7.6)\end{array}$ & $\begin{array}{c}31(46.3) \\
22(32.8) \\
11(16.4) \\
3(4.5)\end{array}$ & $\begin{array}{r}20(30.8) \\
28(43.1) \\
10(15.4) \\
7(10.8)\end{array}$ & -1.70 & .092 \\
\hline Cancer type & $\begin{array}{l}\text { Colorectal } \\
\text { Stomach }\end{array}$ & - & $\begin{array}{r}59(88.1) \\
8(11.9)\end{array}$ & $\begin{array}{l}- \\
-\end{array}$ & - & - \\
\hline Cancer stage & $\begin{array}{l}\text { I, II } \\
\text { III } \\
\text { IV }\end{array}$ & $\begin{array}{l}- \\
-\end{array}$ & $\begin{array}{c}21(31.3) \\
41(61.2) \\
5(7.5)\end{array}$ & $\begin{array}{l}- \\
-\end{array}$ & - & - \\
\hline $\begin{array}{l}\text { Chemotherapy regi- } \\
\text { mens }\end{array}$ & $\begin{array}{l}\text { Oxaliplatin + xeloda } \\
\text { Fluorouracil + leucovorin and/ } \\
\text { or oxaliplatin }\end{array}$ & & $\begin{array}{l}22(32.8) \\
45(67.2)\end{array}$ & & & \\
\hline $\mathrm{Hb}(\mathrm{g} / \mathrm{dL})$ & $\begin{array}{l}<12 \\
\geq 12\end{array}$ & $12.2 \pm 1.53$ & $\begin{array}{l}27(40.3) \\
40(59.7)\end{array}$ & - & - & - \\
\hline
\end{tabular}

nificant differences in cognitive function and fatigue with respect to disease and treatment variables (Table 2).

In the case of the comparison group, there were significant differences on self- reported cognitive decline, depending on the gender $(t=-$ $2.27, p=.027)$, age $(\mathrm{F}=9.04, p<.001)$, marital status $(\mathrm{t}=-3.05, p=.014)$, education $(\mathrm{F}=8.65, p<.001)$, occupation $(\mathrm{t}=-1.75, p=.026)$ and monthly income $(\mathrm{F}=7.25, p<.001)$ (Table 2$)$. Women revealed more cognitive decline than men did, and those over 61 years of age experienced more cognitive decline than those below 60 years. Single participants revealed more cognitive decline than married participants. Those who had a middle school or less education had more cognitive complaints than those with high school education or more. Unemployed and lower income participants revealed more cognitive decline. Unemployed participants revealed more cognitive decline as did those with a lower income. In objective cognitive function, married participants in addition to age $(\mathrm{F}=16.31, p<.001)$, education $(\mathrm{F}=12.25, p<.001)$, occupation $(\mathrm{t}=3.42$, $p=.003)$ and monthly income $(\mathrm{F}=4.09, p=.004)$ showed greater cogni- tive function ( $\mathrm{t}=2.73, p=.024)$. There were significant differences in fatigue according to the marital status $(\mathrm{t}=-2.38, p=.020)$ and education $(\mathrm{F}=6.94, p=.002)$ (Table 2). Single participants revealed higher rates of fatigue as did those with a middle school (or less) education.

\section{Correlations among the variables}

A self-reported cognitive decline showed significant correlations among the objective cognitive function $(\mathrm{r}=-.65, p<.001)$ and fatigue $(\mathrm{r}=.46, p<.001)$. There were significant correlations between objective cognitive function and fatigue $(\mathrm{r}=-.41, p<.001)$. There were no significant correlations among the variables in chemotherapy group. In the case of the comparison group, there were significant correlations among the variables (Table 3).

\section{Changes in cognitive function and fatigue from baseline to follow-up}

Table 4 show the result of repeated measures ANOVA with the 3 time 


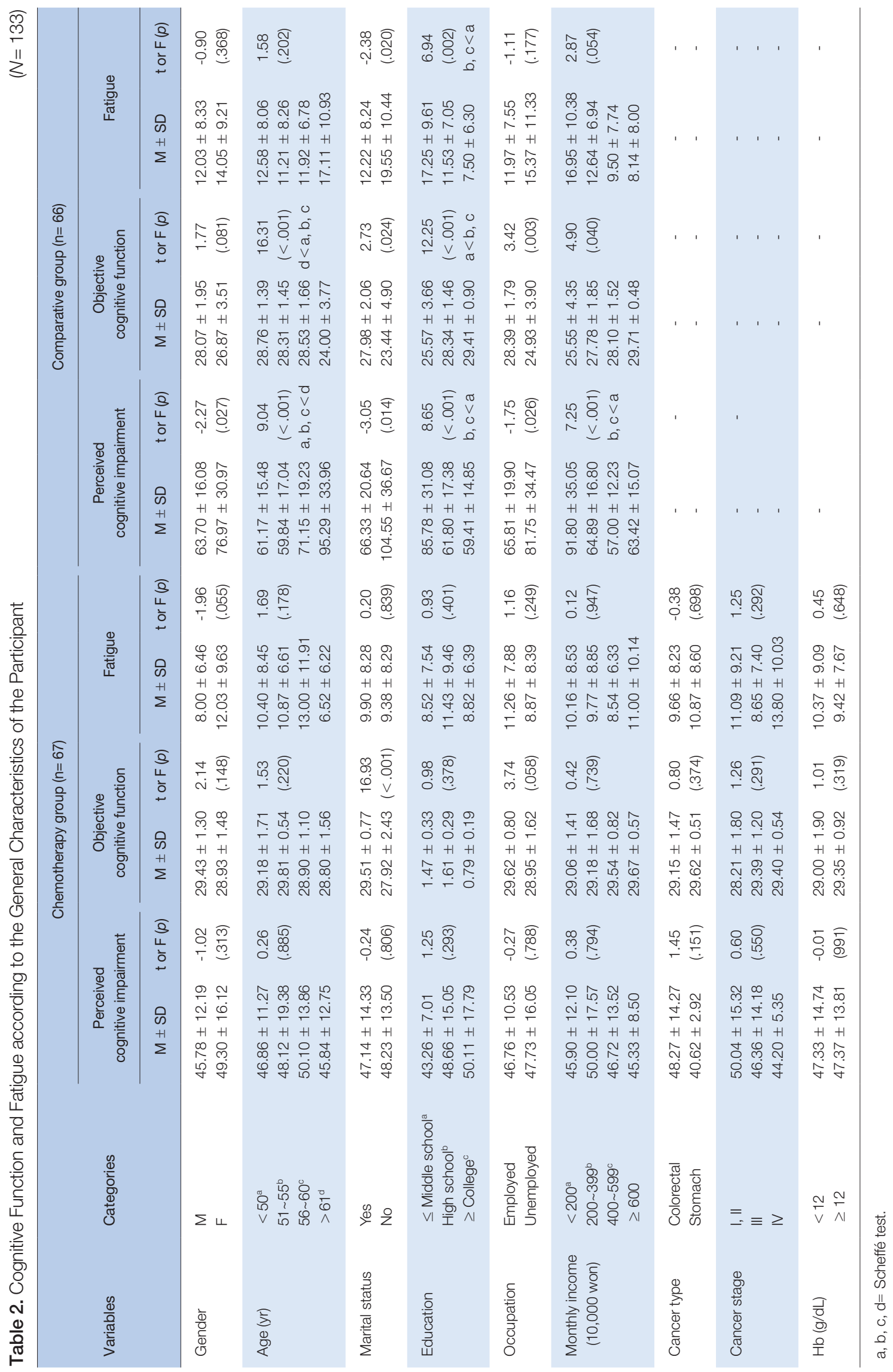


Table 3. Correlations among the Variables

$(N=133)$

\begin{tabular}{|c|c|c|c|c|c|c|c|c|c|}
\hline \multirow{2}{*}{ Variables } & \multicolumn{3}{|c|}{ Chemotherapy group $(n=67)$} & \multicolumn{3}{|c|}{ Comparative group $(n=66)$} & \multicolumn{3}{|c|}{ Total $(n=133)$} \\
\hline & $\mathrm{PCl}$ & OCF & Fatigue & $\mathrm{PCl}$ & OCF & Fatigue & $\mathrm{PCl}$ & OCF & Fatigue \\
\hline $\mathrm{PCl}$ & 1 & $-.11(.386)$ & $.19(.127)$ & 1 & $-.71(<.001)$ & $.57(<.001)$ & 1 & $-.65(<.001)$ & $.46(<.001)$ \\
\hline OCF & & 1 & $.07(.479)$ & & 1 & $-.59(<.001)$ & & 1 & $-.41(<.001)$ \\
\hline Fatigue & & & 1 & & & 1 & & & 1 \\
\hline
\end{tabular}

$\mathrm{PCl}=$ Perceived cognitive impairment; OCF= Objective cognitive function.

Table 4. Changes in Cognitive Function and Fatigue from Baseline to Follow-up

$(N=133)$

\begin{tabular}{|c|c|c|c|c|c|c|c|}
\hline \multirow{2}{*}{ Variables } & \multirow{2}{*}{ Group } & \multirow{2}{*}{$\begin{array}{l}\text { Pre-test }^{a} \\
M \pm S D\end{array}$} & \multirow{2}{*}{$\begin{array}{c}\text { Post-test }^{b} \\
M \pm S D\end{array}$} & \multirow{2}{*}{$\begin{array}{c}\text { Follow-up } \\
M \pm S D\end{array}$} & \multicolumn{2}{|c|}{ Time effect by group } & \multirow{2}{*}{ Bonferron } \\
\hline & & & & & $\mathrm{F}$ & $p$ & \\
\hline $\mathrm{PCl}$ & $\begin{array}{l}\text { Chemotherapy }(n=67) \\
\text { Comparative }(n=66)\end{array}$ & $\begin{array}{l}47.36 \pm 14.09 \\
71.55 \pm 26.60\end{array}$ & $\begin{array}{l}69.54 \pm 24.90 \\
75.92 \pm 29.65\end{array}$ & $\begin{array}{l}48.42 \pm 9.37 \\
70.45 \pm 24.45\end{array}$ & $\begin{array}{r}42.68 \\
2.66\end{array}$ & $\begin{array}{r}<.001 \\
.074\end{array}$ & $a, c<b$ \\
\hline OCF & $\begin{array}{l}\text { Chemotherapy }(n=67) \\
\text { Comparative }(n=66)\end{array}$ & $\begin{array}{l}29.21 \pm 1.40 \\
27.33 \pm 3.06\end{array}$ & $\begin{array}{l}29.31 \pm 1.09 \\
27.05 \pm 3.16\end{array}$ & $\begin{array}{r}28.64 \pm 1.94 \\
27.78 \pm 3.39\end{array}$ & $\begin{array}{l}6.40 \\
5.36\end{array}$ & $\begin{array}{l}.002 \\
.006\end{array}$ & $\begin{array}{c}a, b>c \\
b<c\end{array}$ \\
\hline Fatigue & $\begin{array}{l}\text { Chemotherapy }(n=66) \\
\text { Comparative }(n=66)\end{array}$ & $\begin{array}{r}9.89 \pm 8.26 \\
13.23 \pm 8.86\end{array}$ & $\begin{array}{l}20.65 \pm 10.54 \\
12.15 \pm 8.17\end{array}$ & $\begin{array}{r}8.65 \pm 7.98 \\
11.03 \pm 7.59\end{array}$ & $\begin{array}{r}44.76 \\
3.95\end{array}$ & $\begin{array}{r}<.001 \\
.022\end{array}$ & $\begin{array}{c}a, c<b \\
c<a\end{array}$ \\
\hline
\end{tabular}

a, b, c: Bonferroni post hoc test; $\mathrm{PCl}=$ Perceived cognitive impairment; $\mathrm{OCF}=$ Objective cognitive function.

Table 5. Changes in Number of Cancer Patients Experiencing Cognitive Decline from Baseline to Follow-up

\begin{tabular}{|c|c|c|c|c|c|}
\hline \multirow{2}{*}{ Outcome variables } & \multirow{2}{*}{ Categories } & \multirow{2}{*}{$\begin{array}{c}\text { Pre-test } \\
\mathrm{n}(\%)\end{array}$} & \multicolumn{2}{|c|}{ Post-chemotherapy test Follow-up test } & \multirow{2}{*}{$\begin{array}{c}\text { Cochran test } \\
Q(p)\end{array}$} \\
\hline & & & $\mathrm{n}(\%)$ & $\mathrm{n}(\%)$ & \\
\hline Perceived cognitive decline & $\begin{array}{l}>2 \text { (total) } \\
>2 \text { (female) } \\
>2 \text { (male) }\end{array}$ & $\begin{array}{l}5(7.5) \\
3 \\
2\end{array}$ & $\begin{array}{l}26(38.8) \\
17 \\
9\end{array}$ & $\begin{array}{l}1(1.5) \\
1 \\
0\end{array}$ & $41.61(<.001)$ \\
\hline Everyday memory & $>2$ & $7(10.4)$ & $34(50.7)$ & $3(4.5)$ & \\
\hline Language & $>2$ & $5(7.5)$ & $31(46.3)$ & $3(4.5)$ & \\
\hline Executive function: planning & $>2$ & $4(6.0)$ & $26(38.8)$ & $1(1.5)$ & \\
\hline Executive function: organization & $>2$ & $3(4.5)$ & $20(29.9)$ & $2(3.0)$ & \\
\hline Executive function: divided attention & $>2$ & $8(11.9)$ & $37(55.2)$ & $16(23.9)$ & \\
\hline Visuospatial abilities & $>2$ & $3(4.5)$ & $12(17.9)$ & $4(6.0)$ & \\
\hline Objective cognitive function & $\leq 26$ & $3(4.5)$ & $1(1.5)$ & $10(14.9)$ & $11.20(.004)$ \\
\hline
\end{tabular}

points. Self-reported cognitive decline found a significant main effect of time point in chemotherapy group $(\mathrm{F}=42.68, p<.001)$. In the chemotherapy group, the mean scores of cognitive decline were initially lower (47.36) than in the comparison group, rising significantly at the postchemotherapy (69.54) before dropping to 48.42 at follow-up. Meanwhile, the mean scores of the comparison group were stable across the three time points (mean scores 71.55, 75.92, and 70.45)(F=2.66, $p=.074$ )

Objective cognitive function also showed a significant effect of time point $(\mathrm{F}=6.40, p=.002)$. However, the chemotherapy group revealed lower mean scores at follow-up (28.64) than at the baseline (29.21) and post-chemotherapy (29.31). In the comparison group, the mean scores of objective cognitive function increased significantly at follow-up to 27.78 from 27.05 at the post-test stage $(\mathrm{F}=5.36, p=.006)$.

Table 5 shows the changes in number of cancer patients experiencing cognitive decline from baseline to follow-up. The number of patients experiencing cognitive decline in their daily lives were $7.5 \%$ in the pre- chemotherapy phase, $38.8 \%$ in the post-chemotherapy phase, and $14.9 \%$ in the six months follow-up phase. These changes were significant in the Cochran $\mathrm{Q}$ test $(\mathrm{Q}=41.61, p<.001)$. The domains of cognitive function showed the most decline were divided attention (the ability to process multiple activities or information at the same time)(from 11.9\% to $55.2 \%$ ) and memory (from $10.4 \%$ to $50.7 \%$ ).

The number of patients with scores $\leq 26$ points in objective cognitive function was $4.5 \%$ in the pre-chemotherapy, $1.5 \%$ in the post-chemotherapy, and $14.9 \%$ in the 6 month follow-up. These changes were significant in the Cochran $Q$ test $(\mathrm{Q}=11.20, p<.004)$.

The patterns of cancer-related fatigue were similar to those observed with perceived cognitive function. In the chemotherapy group, the mean scores of fatigue increased significantly at post-chemotherapy (20.64) from 8.89 at pre-chemotherapy and then dropping to 8.65 at follow-up $(\mathrm{F}=44.76, p<.001)$. In the comparison group, fatigue levels were significantly higher at the pre-test (mean score 13.23) than at follow-up 
(mean score 11.03) $(\mathrm{F}=3.95, p=.022)$.

\section{DISCUSSION}

The results of our study showed that there were no differences in $\operatorname{cog}$ nitive function over time for the comparison group $(p=.074)$, whereas in the chemotherapy group, perceived cognitive decline increased significantly at the post-chemotherapy phase before dropping at follow-up phase. This is similar to the result of prior research, ${ }^{26)}$ which stated that objective cognitive decline persistently increased during the chemotherapy period and recovered to its prior level 6 months after the completion of treatment.

In the present study, the percentage of participants complaining of cognitive decline immediately after chemotherapy was $38.8 \%$. This is consistent with the figure of $38.5 \%$ reported in a study done on Korean breast cancer patients. ${ }^{12}$ At $14 \sim 43 \%$, the incidences of cognitive decline after the completion of chemotherapy were also in line with the results of a previous study. ${ }^{27)}$ However, the number of participants in this study with subjective cognitive decline at the start of chemotherapy was only $5(7.5 \%)$. Thus, the results of our study support the hypothesis that chemotherapy affects cognitive function and are consistent with reports of CRCI decreasing over time. ${ }^{3)}$ However, this differs from results in previous studies showing that subjective cognitive decline persists 6 months after chemotherapy in 30.8 39\% of breast cancer patients. ${ }^{6,12)}$ This discrepancy in breast cancer patients is thought to be because of higher perceived cognitive decline in female patients than male patients. This is supported by the fact that, when looking at general characteristics in our study, 17 female patients (mean 75.60) reported greater cognitive decline than 9 male patients (mean 64.62) did at post- chemotherapy.

CTCI is experienced by $15 \sim 80 \%$ of cancer patients and survivors. The variance in incidence rates of CTCI can be attributed to different treatment protocols as well as methodological variations across studies such as use of different definitions, cognitive decline instruments used, and times of assessment of CTCI. ${ }^{1,28)}$ Some studies defined cognitive decline in chemotherapy patients as a score of 1.5 to 2 standard deviations below the mean, when normalized to the data of the control group (healthy individuals, or cancer patients who had not undergone chemotherapy). ${ }^{4,26)}$ Like the present study, other authors have also classified cognitive decline based on the criteria suggested by the instrument.

In our study, the domains of subjective cognitive decline most frequently showing a decline immediately after the completion of chemo- therapy were divided attention (55.2\%) and memory (50.7\%). Six months after the completion of chemotherapy, divided attention (23.9\%) was still the most severely affected domain of cognitive decline. This is consistent with a meta-analysis that found impairments in memory and divided attention (executive function) ${ }^{28)}$ Until now, many studies have reported cognitive decline in breast cancer patients, However, the present study in stomach or colorectal cancer patients found impairments in the same domains of cognitive function, despite using different anticancer agents. Impaired divided attention can cause limitations in learning and memory of self-care information in cancer patients, and render them unable to perform the activities of daily living, work, or social activities smoothly. ${ }^{29)}$ Subjective memory decline refers to the state in which the patient complains that his/her memory has declined even though objective memory tests are within the normal range. ${ }^{30)}$ Our study also found that objective cognitive function scores for the chemotherapy group were within the normal range, with a mean score of 29.31 , and that only 10 participants (14.9\%) showed decreased cognitive function with a score of 26 points or less at 6 months follow-up. However, it should be noted that subjective cognitive decline is associated with early dementia, and reflects a decline in objective cognitive function. ${ }^{30)}$ In particular, aging can induce a decline in cognitive function, which is relevant given that the mean age of the participants in our study was 56 years, and $70.7 \%$ of subjects were aged 50 years or older. Thus, cancer survivors require appropriate education on CRCI, as well as training programs that can help them maintain and improve the cognitive domains of attention and memory.

In the objective measurements of cognitive function, cognitive decline, defined as a score of 26 points or less, increased (14.9\%) at the time point 6 months after the completion of chemotherapy. This supports results from previous studies, in which CRCI persisted long-term in 17 35\% of the participants. ${ }^{1,3)}$ However, the incidence in our study was slightly lower than the $22.0 \%$ reported at 6 months after chemotherapy completion in a Korean study of breast cancer patients. ${ }^{12)}$ This is thought to be because the breast cancer patients were all women, and cognitive decline is more severe in female patients than in male patients. Supporting this, $55.2 \%$ of the participants in our study were male.

From the results stated above, we can deduce that severe subjective cognitive decline developed immediately after chemotherapy, but objective cognitive function remained within the normal range irrespective of chemotherapy (29.31 score), and actually showed some decline at the time point 6 months after chemotherapy completion (28.64 score). This apparent contradiction is related to the fact that the K-MMSE is not sen- 
sitive at detecting the mild cognitive decline shown by cancer patients. ${ }^{1)}$ The MMSE scores of this study can be considered within the normal range. A ceiling effect likely influenced the objective cognitive function measurements obtained by using the K-MMSE. ${ }^{1)}$ In addition, it suggests that CRCI does not involves much of a change in the substance of the brain, but rather a decline in attention and concentration that is perceived in daily living. ${ }^{1 .}$ Although objective cognitive function is measured momentarily, like an image, subjective cognitive function, as measured by self-report, measures changes in cognitive function over a certain period. As a result, subjective cognitive decline can show a higher incidence than objective cognitive impairment, which is affected by the emotional state, experience of physical symptoms, and fatigue ${ }^{28)}$

This fact can be seen in our results, since like the pattern for subjective cognitive function, the patients' fatigue was most severe immediately after chemotherapy, and recovered by the 6-month follow-up examination. Our study showed that fatigue becomes very severe in cancer patients as an adverse effect of chemotherapy, and that the level of fatigue shows a significant correlation with objective cognitive function and subjective cognitive decline. This differs from previous reports, in which fatigue had a strong correlation with subjective cognitive decline, but almost no correlation with objective cognitive function measured in neuropsychological tests. ${ }^{15)}$ Fatigue is the disease/treatment-related factor reported to have the strongest association with cognitive function. ${ }^{15)}$ Our results support the hypothesis that fatigue is correlated to cognitive function in cancer patients, and suggest the need for interventions to manage fatigue and improve cognitive function. Chemotherapy causes toxic injury to cells, and the resulting inflammatory response can cause fatigue due to excessive cytokine production. ${ }^{15)}$ Our study measured hemoglobin levels at an average of $12.2 \mathrm{~g} / \mathrm{dL}$ just before starting chemotherapy, but did not identify any change in hemoglobin levels immediately after the completion of chemotherapy. Future research will be required to verify whether decreased hemoglobin levels after the completion of chemotherapy increase fatigue, and whether decreased oxygen supply to the brain can affect cognitive function. ${ }^{15}$

A unique aspect of our study is that, in the cross-sectional measurements at each time point, the chemotherapy group showed better cognitive function than the comparison group. This phenomenon also appeared in a meta-analysis of CRCI. ${ }^{28)}$ Further investigations are required to find out if engaging in treatment made the cancer patient group more motivated to perform well in cognitive tests, or whether there were differences in education or age that could also affect cognitive function. ${ }^{29)}$ The examination of the general characteristics in our study showed the two groups to be statistically homogeneous, but the comparison group did show a higher mean age (56.06 years) than the chemotherapy group (54.99 years), and a higher proportion of participants with an education level of middle school graduation or lower. Nevertheless, we believe that the primary cause of this difference was the patient group being more motivated ahead of treatment and evaluating their own condition more positively. This can also be seen in the case of fatigue, in which the cancer patient group rated their level of fatigue significantly lower than the healthy individuals.

Although this was a longitudinal study investigating the impact of chemotherapy on cognitive function in stomach or colorectal cancer patients, it was not possible to analyze cognitive impairments that developed in the late stages of treatment because follow-up examinations were performed 6 months after the completion of chemotherapy. The majority of studies on CRCI so far have investigated breast cancer patients, but our results show that the incidence and affected domains of cognitive impairment are similar for patients with stomach or colorectal cancer. This study is significant insofar as it includes the longitudinal assessment of cancer treatment-related fatigue, and also evaluates the correlation between fatigue and cognitive impairment.

\section{CONCLUSION}

This prospective study was done to identify the changes of cognitive function and fatigue at 3 time points: pre-chemotherapy, post- chemotherapy, and 6 months follow-up in people with stomach or colorectal cancer. In the chemotherapy group, self-reported cognitive decline increased significantly at post-chemotherapy $(38.8 \%)$ and improved at the follow-up (1.5\%). At the post-chemotherapy point, patients reported greater difficulty in the cognitive domains of attention and concentration, memory, and executive function.

Self-reported cognitive decline was more common than objectively confirmed cognitive decline. Meanwhile, mean scores of the healthy comparison group were stable across the 3 time points. Similar patterns were observed in cancer-related fatigue as well as cognitive function, suggesting the role of fatigue as a predictor of chemotherapy-related cognitive changes. These results suggest that chemotherapy may be associated with cognitive decline and fatigue in patients with cancer. Nursing programs should be developed to handle interventions for cognitive impairment. 


\section{ORCID}

오복자 orcid.org/0000-0002-5963-5516

문선미 orcid.org/0000-0001-9911-4451

\section{ACKNOWLEDGMENTS}

The authors would like to thank Cha, Seung Mi and Lee, Kyung Eon, Volunteer Research Assistants, Sahmyook University, Seoul, Korea, for providing support during stages of the study process.

\section{REFERENCE}

1. Hutchinson AD, Hosking JR, Kichenadasse G, Mattiske JK, Wilson C. Objective and subjective cognitive impairment following chemotherapy for cancer: a systematic review. Cancer Treat Rev. 2012;38:926-34.

2. Gehring K, Roukema JA, Sitskoorn MM. Review of recent studies on interventions for cognitive deficits in patients with cancer. Expert Rev Anticancer Ther. 2012;12:255-69.

3. Ahles TA, Saykin AJ, Furstenberg CT, Cole B, Mott LA, Skalla K, et al. Neuropsychologic impact of standard-dose systemic chemotherapy in long-term survivors of breast cancer and lymphoma. J Clin Oncol. 2002;20:485-93.

4. Wefel JS, Schagen SB. Chemotherapy-related cognitive dysfunction. Curr Neurol Neurosci Rep. 2012;12:267-75.

5. de Ruiter MB, Reneman L, Boogerd W, Veltman DJ, Caan M, Douaud G, et al. Late effects of high-dose adjuvant chemotherapy on white and gray matter in breast cancer survivors: converging results from multimodal magnetic resonance imaging. Hum Brain Mapp. 2012;33:2971-83.

6. Lange M, Rigal O, Clarisse B, Giffard B, Sevin E, Barillet M, et al. Cognitive dysfunctions in elderly cancer patients: a new challenge for oncologists. Cancer Treat Rev. 2014;40:810-7.

7. Kwon JS, Kim YG, Kim JY, Yuk JS, Cho HJ, Hong SP. Cognitive rehabilitation. Seoul: Pacific Books; 2008. p. 282.

8. Hyrien O, Dietrich J, Noble M. Mathematical and experimental approaches to identify and predict the effects of chemotherapy on neuroglial precursors. Cancer Res. 2010;70:10051-9.

9. Verstappen CC, Heimans JJ, Hoekman K, Postma TJ. Neurotoxic complications of chemotherapy in patients with cancer: clinical signs and optimal management. Drugs. 2003;63:1549-63.

10. Nelson CJ, Nandy N, Roth AJ. Chemotherapy and cognitive deficits: mechanisms, findings, and potential interventions. Palliat Support Care. 2007;5:273-80.

11. Chung BY, Cho EJ. Correlates influencing cognitive impairment in breast cancer patients receiving chemotherapy. Asian Oncol Nurs. 2012;12:221-9.

12. Park JH, Bae SH, Jung YS, Jung YM. Prevalence and characteristics of chemotherapy-related cognitive impairment in patients with breast cancer. J Korean Acad Nurs. 2015;45:118-28.

13. Krynetskiy E, Krynetskaia N, Rihawi D, Wieczerzak K, Ciummo V,
Walker E. Establishing a model for assessing DNA damage in murine brain cells as a molecular marker of chemotherapy-associated cognitive impairment. Life Sci. 2013;93:605-10.

14. Kaiser J, Bledowski C, Dietrich J. Neural correlates of chemotherapy-related cognitive impairment. Cortex. 2014;54:33-50.

15. Vardy J, Tannock I. Cognitive function after chemotherapy in adults with solid tumours. Crit Rev Oncol Hematol. 2007;63:183-202.

16. Oh PJ, Lim SY. Change of cancer symptom, depression and quality of life based on phases of chemotherapy in patients with colorectal or stomach cancer: a prospective study. Korean J Adult Nurs. 2017;29: 313-22.

17. Faul F, Erdfelder E, Lang AG, Buchner A. G*Power 3: a flexible statistical power analysis program for the social, behavioral, and biomedical sciences. Behav Res Methods. 2007;39:175-91.

18. Park JH, Bae SH. A meta-analysis of chemotherapy related cognitive impairment in patients with breast cancer. J Korean Acad Nurs. 2012; 42:644-58.

19. Chung BY, Cho EJ. Correlates influencing cognitive impairment in breast cancer patients receiving chemotherapy. Asian Oncol Nurs. 2012;12:221-9.

20. Tomaszewski Farias S, Mungas D, Harvey DJ, Simmons A, Reed BR, Decarli C. The measurement of everyday cognition: development and validation of a short form of the Everyday Cognition scales. Alzheimers Dement. 2011;7:593-601.

21. Kang YW. A normative study of the Korean-Mini Mental State Examination (K-MMSE) in the elderly. Korean J Psychol Gen. 2006;25:1-12.

22. Folstein MF, Folstein SE, McHugh PR. "Mini-mental state". A practical method for grading the cognitive state of patients for the clinician. J Psychiatr Res. 1975;12:189-98.

23. Prabhu RS, Won M, Shaw EG, Hu C, Brachman DG, Buckner JC, et al. Effect of the addition of chemotherapy to radiotherapy on cognitive function in patients with low-grade glioma: secondary analysis of RTOG 98-02. J Clin Oncol. 2014;32:535-41.

24. Yellen SB, Cella DF, Webster K, Blendowski C, Kaplan E. Measuring fatigue and other anemia-related symptoms with the Functional Assessment of Cancer Therapy (FACT) measurement system. J Pain Symptom Manage. 1997;13:63-74.

25. Chaiy SI. Social science research methodology. 2nd ed. Paju: Hakhyunsa; 2000.p. 82.

26. Jansen CE, Cooper BA, Dodd MJ, Miaskowski CA. A prospective longitudinal study of chemotherapy-induced cognitive changes in breast cancer patients. Support Care Cancer. 2011;19:1647-56.

27. Tager FA, McKinley PS, Schnabel FR, El-Tamer M, Cheung YK, Fang Y, et al. The cognitive effects of chemotherapy in post-menopausal breast cancer patients: a controlled longitudinal study. Breast Cancer Res Treat. 2010;123:25-34.

28. Lindner OC, Phillips B, McCabe MG, Mayes A, Wearden A, Varese F, et al. A meta-analysis of cognitive impairment following adult cancer chemotherapy. Neuropsychology. 2014;28:726-40.

29. Myers JS. Chemotherapy-related cognitive impairment: the breast cancer experience. Oncol Nurs Forum. 2012;39:E31-40.

30. Kang MA, Baek YM. The neurocognitive function between the patients who had subjective memory impairment and mild cognitive impairment. J Korean Geriatr Soc. 2014;18:7-15. 